\title{
Prevalência de casos de HIV/AIDS nos últimos 10 anos no Brasil
}

\author{
Prevalence of HIV / AIDS cases in the last 10 years in Brazil \\ Prevalencia de casos de VIH / SIDA en los últimos 10 años en Brasil
}

Recebido: 22/10/2021 | Revisado: 30/10/2021 | Aceito: 01/11/2021 | Publicado: 03/11/2021

\author{
Rosilda Maria Batista \\ ORCID: https://orcid.org/0000-0003-0069-2767 \\ Centro Universitário UNIFAVIP/WYDEN, Brasil \\ E-mail: rmbatista13@gmail.com \\ Samilla da Silva Andrade \\ ORCID: https://orcid.org/0000-0002-9276-5734 \\ Centro Universitário UNIFAVIP/WYDEN, Brasil \\ E-mail: asamilla30@gmail.com \\ Thamyres Fernanda Moura Pedrosa Souza \\ ORCID: https://orcid.org/0000-0002-2753-4809 \\ Centro Universitário UNIFAVIP/WYDEN, Brasil \\ E-mail: thamyres.souza@professores.unifavip.edu.br
}

\begin{abstract}
Resumo
O Vírus da Imunodeficiência Humana popularmente conhecido como HIV, é o agente causador da AIDS (Síndrome da Imunodeficiência Adquirida), que afeta o sistema imunológico, deixando o organismo infectado susceptível a contrair outras doenças oportunistas causadas por outros vírus, bactérias, fungos ou protozoários que causam complicações podendo levar ao óbito. Os primeiros relatos da AIDS no Brasil surgiram no início da década de 1980, com uma disseminação muito rápida em todas as regiões do país, porém, a prevalência de casos em maior proporção encontra-se até os dias atuais entre os heterossexuais no sul e Sudeste do Brasil. Passaram-se algumas décadas desde a descoberta do HIV, e mesmo o país se posicionando com relação ao enfretamento da doença e com os avanços no tratamento, é nítido que a epidemia está longe de ser controlada, e que os índices de novos casos anuais ainda têm sido bastante expressivos. A presente pesquisa tem por objetivo analisar através de dados estatísticos ao longo dos anos, qual a população é mais acometida pela infecção do HIV/AIDS no Brasil, como se dá o tratamento e qual a sua relação com as doenças oportunistas.
\end{abstract}

Palavras-chave: Infecções sexualmente transmissíveis; HIV; Antirretrovirais.

\begin{abstract}
The Human Immunodeficiency Virus, popularly known as HIV, is the causative agent of AIDS (Acquired Immunodeficiency Syndrome), which affects the immune system, leaving the infected organism susceptible to contracting other opportunistic diseases caused by other viruses, bacteria, fungi or protozoa that cause complications and can lead to death. The first reports of AIDS in Brazil emerged in the early 1980s, with a very rapid spread in all regions of the country, however, the prevalence of cases in a greater proportion is still found today among heterosexuals in the South and Southeast from Brazil. A few decades have passed since the discovery of HIV, and even though the country is positioning itself in relation to the fight against the disease and with advances in treatment, it is clear that the epidemic is far from being controlled, and that the rates of new annual cases are still have been quite expressive. This research aims to analyze through statistical data over the years, which population is most affected by HIV/AIDS infection in Brazil, how the treatment is given and what is its relationship with opportunistic diseases.
\end{abstract}

Keywords: Sexually transmitted infections; HIV; Antiretrovirals.

\section{Resumen}

El Virus de la Inmunodeficiencia Humana, conocido popularmente como VIH, es el agente causante del SIDA (Síndrome de Inmunodeficiencia Adquirida), que afecta al sistema inmunológico, dejando al organismo infectado susceptible a contraer otras enfermedades oportunistas provocadas por otros virus, bacterias, hongos o protozoos que causan complicaciones y puede provocar la muerte. Os primeiros relatos da AIDS no Brasil surgiram no início da década de 1980, com uma disseminação muito rápida em toda as regiões do país, porém, a prevalência de casos em maior proporção encontra-se até os dias atuais entre os heterossexuais no sul e Sudeste de Brasil. Han pasado algunas décadas desde el descubrimiento del VIH, y si bien el país se está posicionando en relación al combate de la enfermedad y con los avances en el tratamiento, es evidente que la epidemia está lejos de estar controlada, y que las tasas de nuevos brotes anuales. Los casos siguen siendo bastante expresivos. Esta investigación tiene como objetivo analizar a través de datos estadísticos a lo largo de los años, qué población es más afectada por la infección por VIH / SIDA en Brasil, cómo se administra el tratamiento y cuál es su relación con las enfermedades oportunistas. 
Palabras clave: Infecciones de transmisión sexual; VIH; Antirretrovirales.

\section{Introdução}

O Vírus da Imunodeficiência Humana popularmente conhecido como HIV, é o agente causador da AIDS (Síndrome da Imunodeficiência Adquirida), que afeta o sistema imunológico, deixando o organismo infectado susceptível a contrair outras doenças oportunistas causadas por outros vírus, bactérias, fungos ou protozoários que causam complicações podendo levar ao óbito. Seu modo de transmissão é principalmente, através do ato sexual desprotegido, atinge diversos grupos independente de sexo, gênero, orientação sexual e idade. Porém, de acordo com as estimativas da Organização Mundial da Saúde - OMS, (2009) a infecção pelo vírus do HIV é mais comum em jovens entre 15 e 24 anos com vida sexual ativa (Santos Lins et al., 2019).

Acredita-se que o vírus da AIDS teve sua origem na metade do século XX, na África Central, por uma mutação do vírus do macaco/chimpanzé, sua transmissão ao homem se deu pelo contato íntimo com esses animais através dos fluidos corporais, consumo da carne do macaco malcozida, ou por meio de arranhões e mordidas provenientes de confrontos entre ambos. A primeira exposição ao homem ocorreu em Los Angeles e São Francisco nos Estados Unidos em homossexuais do sexo masculino com um quadro bem excêntrico de pneumocistose e sarcoma de Kaposi. Com a rápida propagação dos casos de HIV a nível mundial, ocorreram mudanças significativas em diversos campos, não somente na área científica e saúde, como também vieram novos protagonistas em movimentos sociais alcançando um maior número de pessoas independente se sua classe social. (Pinto et al., 2007)

Os primeiros relatos da AIDS no Brasil surgiram no início da década de 1980, com uma disseminação muito rápida em todas as regiões do país, porém, a prevalência de casos em maior proporção encontra-se até os dias atuais no sul do Brasil, com uma maior ênfase no estado do Rio Grande do Sul. Passaram-se algumas décadas desde a descoberta do HIV, e mesmo o país se posicionando com relação ao enfretamento da doença e com os avanços no tratamento, é nítido que a epidemia está longe de ser controlada, e que os índices de novos casos anuais têm sido bastante expressivos colocando o Brasil entre as primeiras posições no ranking de novas infecções pelo HIV na América Latina (Dartora et al., 2017).

Tradicionalmente na epidemia do HIV, existe o considerado grupo de risco que é composto pelos usuários de drogas injetáveis, profissionais do sexo e os homossexuais, por muito tempo esses grupos foram o foco principal para as políticas públicas tornando-as mais enfáticas a respeito das estratégias de prevenção e conscientização para essas determinadas populações. Nesse contexto, os homens heterossexuais foram classificados como categoria geral, não fazendo parte das ações preventivas, tornando-se mais vulneráveis a exposição do vírus por falta de conhecimento. Com base no Boletim Epidemiológico do HIV, com relação a classe de exposição, os homens homossexuais representam $38 \%$ dos casos enquanto os heterossexuais 49\%, atualmente apontando uma maior predominância a essa classe (Knauth et al., 2020).

É comum que a pessoa soropositiva, após ser diagnosticada, se depare com a recusa social, sentindo-se vulnerável pelo receio do preconceito, que é rotulado pela própria sociedade, influenciando diretamente na vida da pessoa infectada, tendo em vista que muitas vezes o meio social usa do diagnóstico como uma justificativa para exclusão do soropositivo. Desde que a AIDS surgiu, é notória a prevalência da discriminação. Devido esses acontecimentos, as pessoas portadoras do vírus HIV acabam optando por não revelarem a sua condição sorológica como uma forma de segurança (Seidl et al., 2010).

Para o desenvolvimento das drogas antirretrovirais foi empregado um alto investimento em pesquisas e tecnologia, principalmente para o monitoramento da qualidade desta terapia, correndo o risco de todo esforço e investimento ser perdido, caso não sejam empregadas estratégias para o aumento da adesão a terapia. O processo de adesão requer que o paciente esteja de comum acordo com a terapia que é prescrita pelo médico e orientada pela equipe de saúde. É necessário um trabalho 
coletivo entre os pacientes e profissionais de saúde, cada parte lidando com a sua responsabilidade para que assim o tratamento seja eficaz (Ribeiro do Vale \& Pagliari, 2017).

A terapia antirretroviral aumentou a longevidade dos indivíduos portadores do vírus HIV, consequentemente elevando o número de comorbidades correlacionada à infecção. Essas possíveis comorbidades requerem o desenvolvimento e incorporação de medicamentos com poucas interações medicamentosas, toxicidade diminuída, elevada barreira genética, baixa carga de comprimidos e custos mínimos. Dessa forma, o desenvolvimento de novos fármacos além das classes de medicamentos mais antigas, tais como: Inibidores de transcriptase reversa análogos de nucleosídeo ou nucleotídeo (ITRN); Inibidores de transcriptase reversa não-nucleosídeos (ITRNNs) ou Inibidores de protease (IPs), têm sido primordiais no tratamento da doença, atingindo um alto percentual de sucesso da terapia (Vieira et al., 2019).

Estudos apontam que um dos métodos responsáveis para o aumento da adesão dos antirretrovirais, é a atenção farmacêutica, dispondo de benefícios clínicos ao paciente e desenvolvendo uma aceitação maior por parte do usuário ao serviço ofertado. A Terapia Antirretroviral (TARV) quando não aderida, acarreta numa diminuição da eficácia do tratamento, consequentemente piorando o estado clínico do usuário, por esse motivo é de grande importância adotar todas as medidas que são orientadas (Matias Pedroso \& De Assis Vitorino, 2019).

A presente pesquisa teve por objetivo analisar através de dados estatísticos ao longo dos anos, qual a população é mais acometida pela infecção do HIV/AIDS no Brasil, como se dá o tratamento e qual a sua relação com as doenças oportunistas.

\section{Metodologia}

O presente estudo foi realizado através de uma pesquisa de campo transversal que teve como fonte pesquisas bibliográficas sobre o HIV/AIDS descrevendo as características do tipo de população mais acometida pela doença de acordo com as suas variáveis através de dados quantitativos.

Vale enfatizar que a pesquisa de campo tem por intuito coletar dados a cerca de um problema com o objetivo de comprovar ou descobrir as relações entre eles (Prodanov \& Freitas, 2013, p. 59)

A pesquisa estatística foi realizada através de informativos disponibilizados no site do Ministério da Saúde, UNAIDS Brasil, UNAIDS Global, e em plataformas do DATASUS como TABNET e Tabwin. A população escolhida para obtenção da amostragem foram: jovens e adultos com idades entre 15 e 40 anos de ambos os sexos e orientação sexual (heterossexual e homossexual).

Foi incluída na pesquisa dissertações, artigos de jornais e revistas, matérias de sites oficiais, livros, documentos e trabalhos publicados nos últimos 15 anos, com os seguintes descritores: HIV e AIDS, DST, reações adversas a antirretrovirais, farmacoterapia da AIDS e doenças oportunistas, Populações mais acometidas como gênero, orientação sexual e idade. E foram excluídas todas as pesquisas que não fazem parte desse grupo populacional em específico.

A coleta de dados foi realizada através de dados estatísticos e epidemiológicos disponibilizados em sites oficiais de órgãos públicos. O processamento e a análise de dados foram feitos por uma pesquisa de campo cujo objetivo foi analisar através de dados estatísticos e epidemiológicos utilizando gráficos e tabelas, quais regiões há um índice mais elevado da doença e quais os fatores que contribuem até os dias atuais para tal resultado.

\section{Resultados e Discussão}

A pandemia do HIV representa uma preocupação a nível global pois afeta diretamente a qualidade de vida do portador do vírus bem como seus direitos humanos, a política de medicamentos e cada região do mundo possui sua particularidade socioeconômica, cultural e com características próprias. Essa situação se torna um imenso desafio para a comunidade científica 
pois a Síndrome da Imunodeficiência humana (AIDS) atinge uma proporção geométrica muito extensa sem qualquer tipo de distinção social. (Pinto et al., 2007)

Determinantes sociais como cultura, raça, cor, situação econômica e etnia, são fatores que estão mais ligados a população afetada pela AIDS/HIV, outro fator importante está relacionado a desigualdade de gênero onde nos EUA (Estados Unidos da América) em média um quinto de novas infecções ao vírus ocorrem em mulheres negras deixando assim evidente a falta de planejamento ao controle da doença deixando consequentemente uma maior vulnerabilidade na saúde de mulheres negras. É necessário mecanismos mais eficazes para prevenção, tratamento e uma maior assistência com o objetivo de diminuir o efeito devastador que essa epidemia vem causando há algumas décadas na população. (Alexander, 2020)

$\mathrm{Na}$ tabela 1 observa-se aumento da progressão gradativa de pessoas vivendo com HIV nos últimos 15 anos e do aumento de pessoas com acesso a terapia de antirretroviral e em contrapartida a diminuição de novas infecções entre pessoas acima de 15 anos de idade bem como a diminuição de mortes relacionadas a AIDS.

Dados estatísticos globais (Tabela 1) sobre o HIV divulgados pela UNAIDS em julho de 2021 é que existem cerca de 37,6 milhões de pessoas no mundo vivendo com HIV até o fim de 2020 e cerca de 27,4 milhões de pessoas possuem acesso a terapia com antirretrovirais. O índice de novas infecções pelo HIV até o final de 2020 foi por volta de 1,5 milhões no total, apesar de serem dados bastantes relevantes, houve redução de novas infecções em $47 \%$ desde o pico que aconteceu no ano de 1998. Devido ao aumento do acesso a farmacoterapia houve uma queda bastante relevante da mortalidade relacionada à AIDS, as mortes diminuíram cerca de $42 \%$ desde 2010. Mas diante desse cenário é de extrema importância que os países redobrem esforços e atuem com maior agilidade para atingir os milhões de pessoas que ainda estão sendo deixadas para trás. (UNAIDS, 2021).

Tabela 1: Estatísticas globais sobre o HIV 2005 a 2020.

\begin{tabular}{|c|c|c|c|c|}
\hline \multicolumn{5}{|c|}{ Estatísticas globais sobre o HIV 2005 a 2020} \\
\hline & 2005 & 2010 & 2015 & 2020 \\
\hline $\begin{array}{l}\text { Pessoas que } \\
\text { vivem com HIV }\end{array}$ & 27,4 milhões & 30,4 milhões & 34,2 milhões & 37,6 milhões \\
\hline $\begin{array}{l}\text { Novas infecções } \\
\text { por HIV (15+ } \\
\text { anos) }\end{array}$ & 1,9 milhão & 1,8 milhão & 1,6 milhão & 1,3 milhão \\
\hline $\begin{array}{l}\text { Novas infecções } \\
\text { por HIV (total) }\end{array}$ & 2,4 milhão & 2,1 milhão & 1,8 milhão & 1,5 milhão \\
\hline $\begin{array}{l}\text { Pessoas com } \\
\text { acesso à terapia } \\
\text { antirretroviral }\end{array}$ & 2 milhões & 7.8 milhões & 17,1 milhões & 27,4 milhões \\
\hline
\end{tabular}

Fonte: UNAIDS (2021).

Há uma meta instituída pelo Programa das Nações Unidas sobre o HIV de pôr fim a epidemia pelo vírus até 2030, que necessitará de esforços bem desenvolvidos com algumas parcerias multisetoriais, ações baseadas em evidências e apoio universal. O objetivo é que as pessoas diagnosticadas com a AIDS recebam a terapia antirretroviral (TARV) continuadamente para atingir a supressão viral. De acordo com a OMS (Organização Mundial da Saúde) que estabelece que a adesão ao tratamento deve ocorrer com base em uma dieta equilibrada, uso constante do medicamento, mudanças no hábito de vida da pessoa em concordância com a recomendação do profissional de saúde. Essa adesão envolve cinco dimensões que são basicamente os aspectos socioeconômicos, relacionados ao paciente, relacionados a doença, ao tratamento e ao sistema em conjunto com a equipe de saúde. (Zuge et al., 2020). 


\subsection{Acesso ao tratamento de HIV no brasil}

Em 1996, foi decretada a lei federal 9.313, que garante o acesso à terapia antirretroviral por meio do Sistema Único de Saúde (SUS). Os estudos apontam o quanto essa política pública contribuiu significativamente para a diminuição da mortalidade e dos internamentos por HIV/AIDS no país (BROJAN, et al 2020). Com o passar dos anos e os avanços no cuidado e no tratamento com antirretrovirais, o HIV passou a ter uma condição crônica, fazendo com que o modelo criado apenas nos serviços especializados se mostrasse escassos. A partir dessa realidade o Ministério da Saúde notou a necessidade de se aprimorar de acordo com a nova realidade epidemiológica, assim incorporou a Atenção Primária à Saúde (APS) como parte da rede de serviços, incorporada no cuidado aos portadores de HIV, proporcionando uma ampliação ao acesso aos serviços de saúde (Astolfo et al., 2018).

Criou-se um Sistema de Controle Logístico de Medicamentos (SICLOM) com o intuito de gerenciar a logística dos medicamentos antirretrovirais (ARV) no Brasil. Com esse sistema é possível que o Departamento de Infecções Sexualmente Transmissíveis, se mantenha atualizado em relação ao fornecimento dos medicamentos ARV em várias localidades do país. Os dados são importantes para que se tenha acesso aos diferentes esquemas farmacológicos dos pacientes de AIDS em TARV e principalmente para que haja controle dos estoques e da distribuição dos ARV. O SICLOM acaba se mostrando uma ferramenta de grande valia para a gestão do medicamento em todo o ciclo da Assistência Farmacêutica, auxiliando para que o farmacêutico saia do papel de dispensador de medicamento para o de consultor, aumentando o contato do usuário com o profissional farmacêutico, que é indispensável na equipe multiprofissional (Ribeiro do Vale \& Pagliari, 2017).

Além da promoção do tratamento medicamentoso de forma gratuita, outra estratégia implementada é o diagnóstico e o tratamento precoce das pessoas infectadas pelo HIV. Essas estratégias são promovidas na Atenção Primária à Saúde, por meio de testes rápidos, seguido da TARV, que apresenta eficácia, aumentando os níveis de sobrevida, diminuindo a incidência de novos casos e minimizando o número de mortalidade e morbidade pela AIDS, que é o estágio avançado da infecção pelo HIV. O diagnóstico e tratamento precoce faz com que essa doença deixe de ser caracterizada como letal e passe a ser uma doença crônica de potencial controle (Primeira et al., 2018).

No Gráfico 1 observa-se a prevalência dos casos de AIDS entre os heterossexuais e homossexuais nas cinco regiões do Brasil entre 2010 e 2020, notando- se que em ambas regiões existe uma predominância em pessoas heterossexuais.

Há quatro décadas da epidemia pelo HIV no Brasil e é evidente que a prevalência da AIDS ocorre em pessoas heterossexuais (Gráfico 1) e com tendência de crescimento maior no sexo masculino. Foi estipulado ao longo da história que as classes de risco a contrair o vírus seriam os usuários de drogas injetáveis transmitido por via sanguínea através do compartilhamento de seringas, profissionais do sexo e os homossexuais. E é nesse contexto culturalmente criado que até os dias atuais é tão intensa a transmissão da infecção entre os heterossexuais através do sexo desprotegido por acreditarem erroneamente que estão "seguros” de qualquer contaminação relacionada à AIDS (Knauth et al., 2020). 
Gráfico 1: Prevalência de casos de aids entre heterossexuais e homossexuais no Brasil entre 2010 e 2020

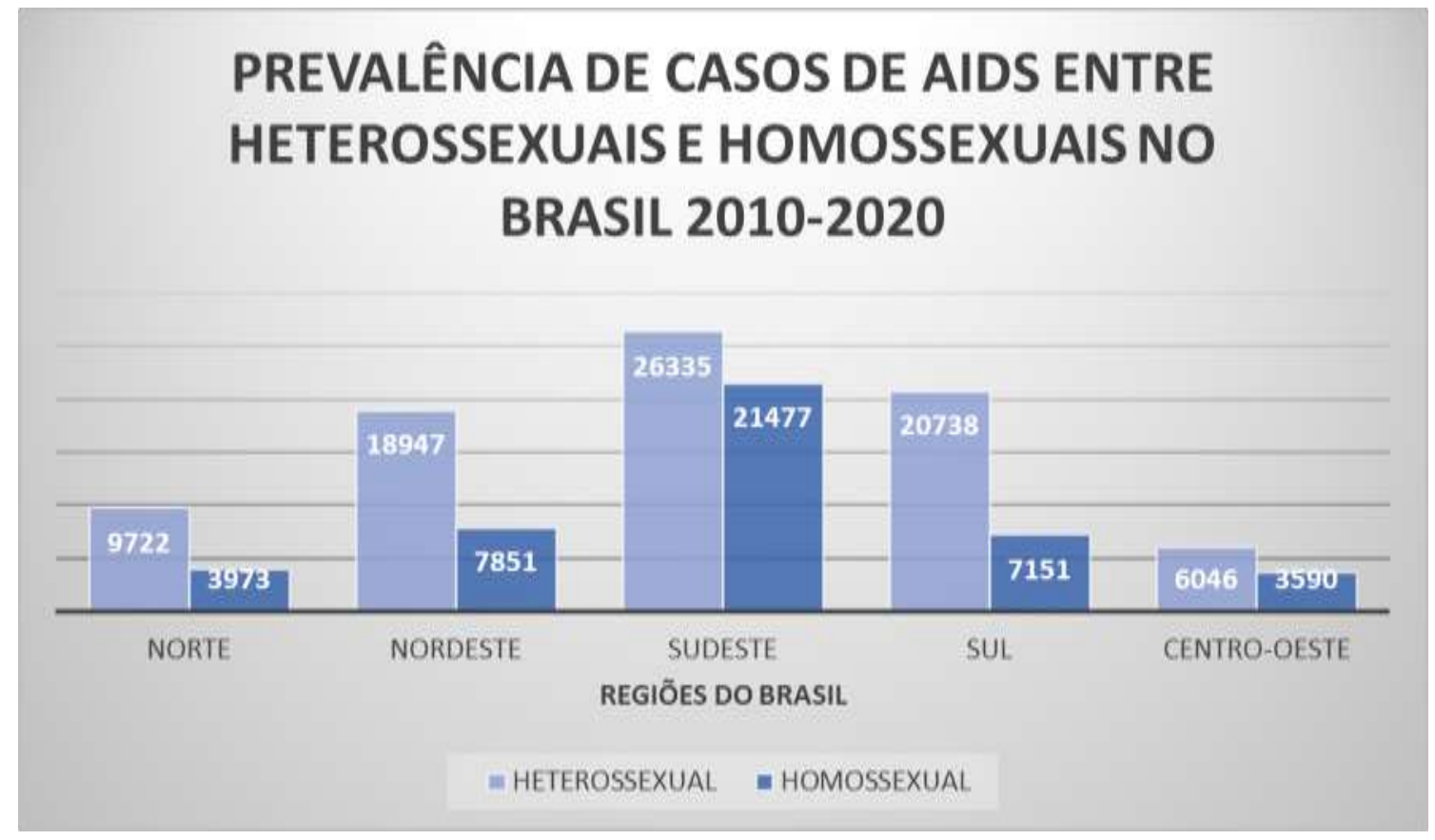

Fonte: DATASUS (2021)

No Gráfico 2 observa-se as mortes relacionadas à AIDS causadas por doenças oportunistas no Brasil que aconteceram entre 2005 a 2020. É notório que esses números tem sido cada vez mais decrescentes, no entanto, esses dados devem ser encarados com bastante cautela.

Gráfico 2: Mortes relacionadas à AIDS causadas por doenças oportunistas no Brasil.

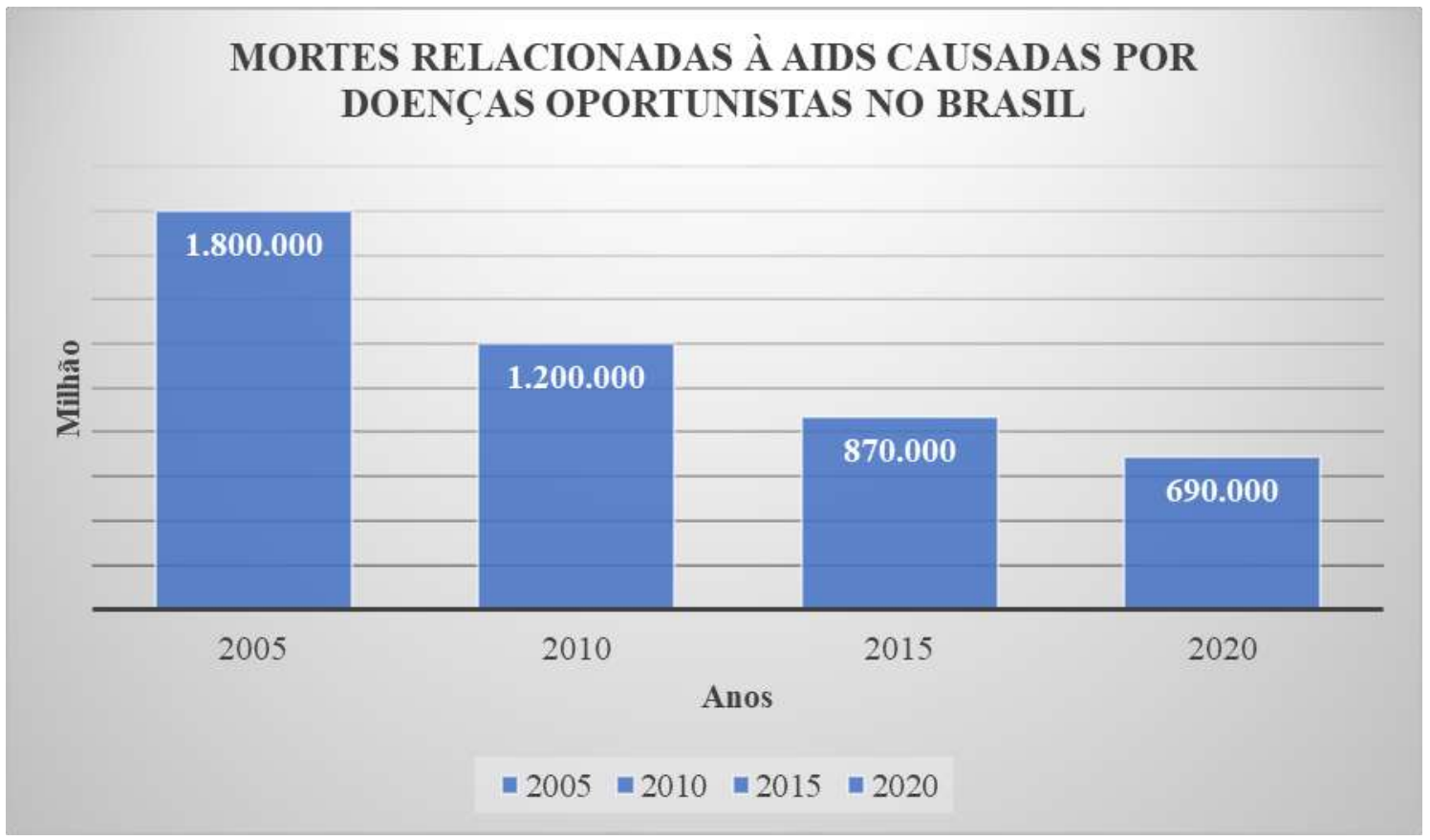

Fonte: UNAIDS (2021).

As doenças oportunistas e outras complicações decorrentes da imunodeficiência são as principais causas de morbimortalidade em doentes com AIDS. Com o agravamento do déficit imunológico, eleva-se a probabilidade de instalação 
de infecções oportunistas. Conforme o número de linfócitos CD4+, a ocorrência de algumas infecções torna-se mais suscetíveis que outras. A possibilidade de desenvolver uma infecção oportunista depende do risco de exposição a patógenos potenciais, a virulência dos patógenos e o nível de imunossupressão do paciente. As infecções oportunistas que ocorrem mais comumente no Brasil, em doentes com AIDS, são constituídas por candidíase (esôfago, traqueia, brônquios e/ou pulmão), pneumocistose (pneumonia por Pneumocystis jiroveci), tuberculose, toxoplasmose, herpes simples, criptococose e criptosporidíase (Quaresma et al., 2019).

\section{Considerações Finais}

Por meio desse estudo foi possível observar que existe um aumento gradativo de pessoas que vivem com HIV sendo um número bem considerável, no entanto o número de pessoas que tem acesso a TARV não cresce na mesma proporção, o que significa dizer que as pessoas não estão tendo acesso ao tratamento seja por recusa ou alguma dificuldade. Também foi possível mais uma vez desmistificar a ideia que ainda é muito presente na sociedade, onde as pessoas associam o HIV/AIDS a homossexualidade, quando na realidade os números mostram que é uma doença de predominância em indivíduos heterossexuais, não tendo o gênero como um fator determinante da doença. As doenças oportunistas é um fator de agravamento muito importante, mesmo apresentando números decrescentes ainda são valores consideráveis de pessoas que vivem com aids e depois de contraírem doenças oportunistas chegam a óbito.

Sugerimos que sejam realizados estudos mais aprofundados a respeito do acesso a TARV e de possíveis falhas no tratamento, para que com base nisso todas as pessoas que vivem com aids possam usufruir da terapia e quem sabe com o acesso ampliado, isso até reflita positivamente na diminuição de novos casos.

\section{Agradecimentos}

Agradecemos primeiramente a Deus, por toda sabedoria nos dada ao longo desse trabalho. Ao apoio e compreensão dos nossos familiares e amigos ao longo da caminhada. A nossa querida orientadora, por todo apoio e orientação nos dada.

\section{Referências}

Alberto, S. A. P., \& Amadei, J. L. (2018). Estratificação de Indivíduos com HIV/AIDS Considerando Aspectos Demográficos e Contagem de Células Cd4/Cd8 em Hospital Provincial de Angola, África. Ensaios e Ciência C Biológicas Agrárias e da Saúde, 22(3), $179-185$.

Alexander, KA (2020). Determinantes sociais do HIV / AIDS e da violência entre parceiros íntimos: interrogando o papel da raça, etnia e cor da pele.

Angelim, R. C. D. M., Brandão, B. M. G. D. M., Oliveira, D. C. D., \& Abrão, F. M. D. S. (2018). Despertar das políticas públicas de combate à AIDS na perspectiva de profissionais de saúde. Rev. pesqui. cuid. fundam. (Online), 913-918

Arruda, P. L. (2019). O papel potencial das transferências sociais na luta contra o HIV/AIDS na África Subsaariana (No. 424).

Astolfo, S., Kehrig, R. T., \& Oliveira, L. R. D. (2018). Disponibilidade de recursos dos serviços ambulatoriais do Sistema Único de Saúde destinados a pessoas vivendo com HIV em Mato Grosso, 2016. Epidemiologia e Serviços de Saúde, 27.

Brasil. Ministério da Saúde. Banco de dados do Sistema Único de Saúde - DATASUS. http://www.datasus.gov.br.

Brojan, L. E. F., Marca, L. M, Dias, F. A., \& Rattmann, Y. D (2020). Uso de medicamentos antirretrovirais por pessoas que vivem com HIV / AIDS e cumprimento do Protocolo Clínico e Diretrizes de Terapia. Einstein (São Paulo), 18 anos.

Cavalin, R. F, Pellini, A. C. G., Lemos, R. R. G. D., \& Sato, A. P. S. (2020). Coinfecção TB-HIV: distribuição espacial e temporal na maior metrópole brasileira. Revista de Saúde Pública, 54 .

Dartora, W. J., Ânflor, É. P., \& da Silveira, L. R. P. (2017). Prevalência do HIV no Brasil 2005-2015: dados do Sistema Único de Saúde. Revista Cuidarte, 8(3), 1919-1928.

Knauth, D. R., Hentges, B., Macedo, J. L. D., Pilecco, F. B., Teixeira, L. B., \& Leal, A. F. (2020). O diagnóstico do HIV/aids em homens heterossexuais: a surpresa permanece mesmo após mais de 30 anos de epidemia. Cadernos de Saúde Pública, 36, e00170118. 
Research, Society and Development, v. 10, n. 14, e336101422149, 2021

(CC BY 4.0) | ISSN 2525-3409 | DOI: http://dx.doi.org/10.33448/rsd-v10i14.22149

Lins, M. E. V. S., de Jesus, J. B., de Oliveira, J. F., Rêgo, G. G., de Matos, A. V. M., Wanderley, N. B., ... \& de Souza, M. B. R. (2019). Perfil epidemiológico de óbitos por HIV/AIDS na região nordeste do Brasil utilizando dados do sistema de informação de saúde do DATASUS/Epidemiological profile of HIV/AIDS deaths in northeastern Brazil using data from the DATASUS health information system. Brazilian Journal of Health Review, 2(4), $2965-2973$.

Pedroso, W. M., \& de Assis Vitorino, K. (2019). Atenção farmacêutica no tratamento de crianças portadores da aids/hiv. Revista Científica da Faculdade de Educação e Meio Ambiente, 10(1), 34-43.

Pinto, A. C. S., Pinheiro, P. N., Vieira, N. F., \& Alves, M. D. S. (2007). Compreensão da pandemia da AIDS nos últimos 25 anos. DST J Bras Doenças Sex Transm, 19(1), 45-50.

Primeira, M. R., dos Santos, É. E. P., Züge, S. S., de Souza Magnago, T. S. B., de Paula, C. C., \& de Mello Padoin, S. M. (2018). Avaliação da adesão ao tratamento antirretroviral de pessoas vivendo com HIV. Saúde e Pesquisa, 11(2), 307-314.

Prodanov, C. C., \& De Freitas, E. C. (2013). Metodologia do trabalho cientifico: métodos e técnicas da pesquisa e do trabalho acadêmico. Editora Feevale.

Quaresma, M. D. S. M., Souza, R. S. A., Barreira, C. P. D. M., de Oliveira, A. S. R., Pontes, C. D. N., \& da Silva, Y. J. A. (2019). Prevalência de doenças oportunistas em pacientes HIV positivos em uma unidade de referência da Amazônia. Revista Eletrônica Acervo Saúde, 11(5), e306-e306.

Ribeiro do Vale, F. V. V., \& Pagliari, C. (2017). Atenção farmacêutica como estratégia para o uso racional de medicamentos antirretrovirais. Braz. J. Surg. Clin. Res, 20(1), 31-37.

Santos Vieira, T., dos Santos Vieira, I., Bresser, M., Moura, L. C. L., \& de Assis Moura, M. (2018). O papel do dolutegravir na terapia antiretroviral. HU Revista, 44(3), 379-385

Seidl, E. M. F., Ribeiro, T. R. A., \& Galinkin, A. L. (2010). Opiniões de jovens universitários sobre pessoas com HIV/AIDS: um estudo exploratório sobre preconceito. Psico-USF, 15, 103-112.

Teixeira, L. D. S. L., Ceccato, M. D. G. B., Carvalho, W. D. S., Costa, J. D. O., Bonolo, P. D. F., Mendes, J. C., \& Silveira, M. R. (2020). Prevalência e fatores associados ao tabagismo em pessoas vivendo com HIV em tratamento. Revista de Saúde Pública, 54.

Unaids - Programa Conjunto das Nações Unidas sobre HIV / AIDS. (2021). Estatísticas mundiais sobre o HIV. https:// aidsinfo.unaids.org.

Zuge, S. S., Paula, C. C. D., \& Padoin, S. M. D. M. (2020). Efetividade de intervenções para adesão à terapia antirretroviral em adultos com HIV: revisão sistemática. Revista da Escola de Enfermagem da USP, 54. 